\title{
APROPRIAÇÕES DO TEMPO PRESENTE NO LIVRO DIDÁTICO DE HISTÓRIA: \\ O CASO DAS JORNADAS DE JUNHO DE 2013
}

\section{PRESENT TIME APPROPRIATIONS IN HISTORY TEXTBOOK: THE CASE OF THE 2013 JUNE JOURNEYS}

\author{
Flávia Eloisa Caimi ${ }^{1}$ \\ Letícia Mistura ${ }^{2}$
}

\begin{abstract}
RESUMO: Parte-se do pressuposto de que o tempo presente constitui um objeto de análise privilegiado do historiador, cuja contribuição é produzir reflexões de natureza histórica que combatam o efêmero, produzam sentidos da experiência diante do esquecimento e forneçam elementos de inteligibilidade do contexto. Investiga-se como o tema das Jornadas de Junho de 2013 é apresentado nos livros didáticos de História, tomando como corpus as 19 coleções inscritas no PNLD 2017, destinadas aos anos finais do ensino fundamental. Em tal corpus, analisa-se a narrativa historiográfica adotada, as propostas de atividades, as interpelações positivas e negativas atribuídas ao assunto, os materiais que subsidiam o tema e, por fim, as orientações destinadas aos professores para ancorar a abordagem em sala de aula, conforme disposto no Manual do Professor. Conclui-se que a narrativa das Jornadas de Junho de 2013 nos livros didáticos de História é predominantemente descritiva, baseada em fontes jornalísticas, com restritas possibilidades de estabelecer análises diacrônicas do fenômeno. Há, todavia, abordagens que trazem os eventos de forma problematizadora, expondo a conjuntura a partir de diversos ângulos e dando voz a diferentes sujeitos/grupos sociais
\end{abstract}

Palavras-chave: História do tempo presente. Livro Didático de História. Jornadas de Junho.

\begin{abstract}
We follow the theoretical assumption that the present consists in a privileged object of analysis for the historian, whose contribution is to produce historical reflection that combat the ephemeral, generate senses of experience in face of forgetfulness, and provides elements of context intelligibility. We investigate how the theme of the 2013 June Journeys is presented by the History textbook, taking as corpus the 19 collections inscribed in the PNLD 2017, destined
\end{abstract}

1 Doutora em Educação pela Universidade Federal do Rio Grande do Sul (2006) e pósdoutora pela Flacso/Argentina (2014). Professora do Programa de Pós-Graduação em Educação (Mestrado e Doutorado) e da Licenciatura em História da Universidade de Passo Fundo/RS.

${ }^{2}$ Mestranda em Educação na Universidade de Passo Fundo/RS. Graduada em História. 
to the final years of Elementary School. From this corpus, we analyze the historiographic narrative adopted, the proposals for activities, the positive and negative interpellations attributed to the subject, the materials that subsidize the subject and, finally, the guidelines for teachers to anchor the approach in the classroom, as provided by the Teacher's Manual. Our conclusion is that the narrative of the 2013 June Journeys in the History textbooks is predominantly descriptive, based on journalistic sources, with restricted possibilities to establish diachronic analysis of the phenomena. There are, however, approaches that address the events in a problematizing way, exposing the conjuncture from several angles and giving voice to different subjects/ social groups.

Keywords: Present History. History textbook. June Journeys.

\section{Introdução}

Se nosso presente é doravante uma sucessão de flashes, de delírios partidários e de jogos de espelhos, como sair dele para erigi-lo, em objeto de investigação histórica? (RIOUX, 1999, p. 41).

Um dos mais extensos e polêmicos debates no âmbito da escrita da História é formulado em termos epistemológicos, ao perguntar se o tempo presente pode se constituir como objeto de investigação histórica. Tal discussão vem gerando diferentes e divergentes posições ao longo de muitas décadas. Os dissensos iniciam pela própria denominação: história recente, história imediata, história próxima, história do tempo presente, história do presente? Essa questão conceitual não apresenta nitidez entre os autores, evidenciando imprecisões em seu uso e caracterizações negativas, ou seja, há maior ênfase em mostrar o que a História do presente não é, do que em especificar a sua conceituação ou caracterização. Os litígios prosseguem frente às tentativas de delimitar o recorte temporal que abarca os acontecimentos mais próximos: semanas, meses, anos ou décadas? As diferentes designações dadas têm em comum a ideia de que o objeto de estudo do historiador é o passado próximo e "são expressivas da opção por uma temporalidade repleta de dificuldades para demarcar datas e estabelecer limites cronológicos precisos e definidos" (DELGADO; FERREIRA, 2013, p. 24). Neste estudo, pautamo-nos pela conceituação 
fornecida por Hobsbawm (1995, 2011), assim sistematizada por Delgado e Ferreira (2013, p. 23):

[...] o tempo presente é o período durante o qual se produzem eventos que pressionam o historiador a revisar a significação que ele dá ao passado, a rever as perspectivas, a redefinir as periodizações, isto é, olhar, em função do resultado de hoje, para um passado que somente sob essa luz adquire significação.

Para além dos embaraços semânticos ou da fluidez cronológica, a pergunta fundante é se o presente pode ser objeto da História (CHAUVEAU; TÉTART, 1999; RIOUX, 1999; HOBSBAWM, 1995; FICO, 2012; HARTOG, 2013). Num breve percurso entre os autores, sem entrar nas especificidades conceituais, pode-se associar a História imediata mais com as técnicas jornalísticas do que com os procedimentos da ciência histórica, conforme afirmam Chauveau e Tétart (1999, p. 22). A análise formulada no calor dos acontecimentos comporta falhas, esquecimentos voluntários ou intencionais, sofre pressões exteriores e coações do tempo veloz dos acontecimentos. Por isso, a História imediata requer, como todas as demais análises, constantes releituras e reformulações, devendo "ser considerada antes de tudo como testemunho, como objeto histórico" (CHAUVEAU; TÉTART, 1999, p. 24-25), ao passo que a História do presente, segundo esses autores, situa-se no campo da pesquisa científica e opera com os instrumentos e critérios que lhes são próprios. De qualquer modo, Chauveau e Tétart (1999, p. 27) reconhecem que a História imediata e a História do presente se complementam e "são vetores da inteligibilidade do presente para um público ampliado e solicitante".

Para Hobsbawm (1995), escrever a História de seu próprio tempo é um desafio para o historiador, que se depara com três principais problemas: 1) o problema da época de nascimento e os problemas geracionais entre jovens e antigos historiadores; 2) o problema da perspectiva sobre o passado e de como as mudanças, que ocorrem no curso dos acontecimentos e do processo histórico, incidem sobre o olhar do historiador, tendo em vista que "o registro do passado se modifica à luz da história subsequente" (p. 109); 3) o problema de como escapar dos pressupostos compartilhados, 
uma vez que o padrão geral das ideias sobre o próprio tempo se impõe à observação dos historiador.

Rioux (1999), por sua vez, considera desconcertante a expressão História do presente, mostrando que não se trata do período mais recente, nem de um conceito de substituição para a crise da temporalidade em sociedades tomadas pelo efêmero, tampouco diz respeito a um meio regulador do caos instalado nas ciências sociais. A preocupação deste autor, a exemplo de outros, é com a possibilidade de constituir uma reflexão de natureza histórica que combata o efêmero, que produza sentidos da experiência histórica, que mostre evidências científicas diante do esquecimento, da amnésia ou do delírio ideológico. Nesse sentido, questiona afirmativamente:

[...] como não sentir, além disso, que uma reflexão histórica sobre o presente pode ajudar as gerações que crescem a combater a atemporalidade contemporânea, a medir o pleno efeito destas fontes originais, sonoras e em imagens, que as mídias fabricam, a relativizar o hino à novidade tão comumente entoado, a se desfazer desse imediatismo vivido que aprisiona a consciência histórica como a folha de plástico 'protege' no congelador um alimento que não se consome? (RIOUX, 1999, p. 46).

A ciência histórica se constituiu alicerçada em preceitos metodológicos que advogavam o imperativo do distanciamento temporal do historiador frente ao seu objeto, segundo o entendimento de que se deveria trabalhar com processos históricos cujos desfechos fossem conhecidos. Quando os temas tratados mantêm uma distância temporal entre o sujeito, o fato e a interpretação do fato, as disputas em torno das narrativas historiográficas seriam amenizadas porque, em tese e de forma equivocada, entende-se que tais conhecimentos não provocam ações e reações diretamente relacionadas ao convívio contemporâneo. No trato de temas recentes sobre os quais grupos distintos disputam qual a narrativa a ser legitimada, e considerando que tais grupos partem da possibilidade da existência de uma "verdade única", o reconhecimento das diferentes vozes é condição primeira para a apresentação de temas dessa natureza, seja na historiografia, seja nos livros didáticos. 
De acordo com Fico (2012, p. 44), "uma das principais peculiaridades da História do Tempo Presente é a pressão dos contemporâneos ou a coação pela verdade, isto é, a possibilidade desse conhecimento histórico ser confrontado pelo testemunho dos que viveram os fenômenos que busca narrar e/ou explicar". Essa forte imbricação com a política, na perspectiva do autor, decorre do fato de que sujeito e objeto estão ambos mergulhados na mesma temporalidade, que ainda está sendo. De fato, a marca central da história do tempo presente - seu entrelaçamento com a política decorre da circunstância de estarmos, sujeito e objeto, mergulhados em uma mesma temporalidade que, por assim dizer, não terminou.

Ancoradas na compreensão de que o tempo presente precisa ser objeto de análise do historiador, de modo a se reconhecer as circunstâncias históricas que conduzem a determinado status quo, a desnaturalizar as práticas do nosso tempo e a evidenciar que elas são fruto de ações, conflitos e lutas históricas, propomos investigar como o tema das Jornadas de Junho de 2013 é apresentado nos livros didáticos de História (LDH), inscritos no edital do PNLD 2017. Considerando que os livros disponibilizados no Guia do PNLD 2017 foram avaliados entre o final de 2015 e início de 2016 e produzidos/revisados em 2014-2015, a incorporação do tema das Jornadas ocorreu "no calor dos acontecimentos", sem o distanciamento temporal requerido por algumas vertentes historiográficas. Mediante tal intencionalidade, tomamos como corpus documental as 19 coleções de História inscritas no PNLD 2017, destinadas aos anos finais do ensino fundamental (60 ao $9^{\circ}$ ano $)^{3}$.

\section{O tempo presente no livro didático e na História escolar}

Questionamentos sobre o que se ensina e como se ensina na escola, na disciplina História, são comuns em qualquer sociedade democrática. Em contextos nos quais as disputas pelo passado podem, de forma drástica,

\footnotetext{
${ }^{3}$ As coleções analisadas fazem parte do acervo pessoal das pesquisadoras. Estão disponíveis também em bibliotecas de escolas públicas e no acervo do Memorial do PNLD, na Universidade Federal do Rio Grande do Norte. Disponível em: https://cchla.ufrn.br/pnld/
} 
definir os contornos do futuro, tais debates ficam acirrados e tornam ainda mais necessária a vinculação do que se ensina na escola ao saber de referência: o conhecimento produzido por meio da análise exaustiva de fontes, de métodos rigorosos, de campos explicativos claramente anunciados, enfim, saberes produzidos a partir do uso de regras que regem a pesquisa histórica.

Ocorre que há temas que compõem os livros didáticos sobre os quais não se têm ainda abordagens apoiadas na ciência de referência. Para tratar de tais temas, os autores de livros didáticos recorrem a informações que estão disponíveis e/ou criam suas próprias versões sobre os fatos. $\mathrm{Na}$ maioria das vezes, a fonte mais acessível é a cobertura jornalística dos eventos. Um fator agravante é que os livros didáticos possuem uma temporalidade determinada quanto à sua produção, avaliação e utilização nas escolas. Em contextos de grandes mudanças no cenário político, econômico ou social de um país, não há como exigir que a abordagem de acontecimentos do tempo presente seja efetuada considerando todo o movimento social em curso. O livro trará sempre o preconizado nas leis, com recortes específicos definidos em edital e no diálogo constante, ainda que precário em alguns casos, com a ciência de referência, ou seja, com o saber histórico produzido e legitimado no âmbito acadêmico.

No campo da História, ao longo de décadas o movimento foi no sentido de incorporar nos editais que regulamentam o PNLD, em cada uma de suas etapas, as concepções mais atuais sobre o processo epistemológico que envolve a construção da aprendizagem histórica na escola. Nessa direção, ampliou-se consideravelmente nos editais a normativa em torno do livro didático de História, com vistas a coibir a veiculação de verdades absolutas, narrativas únicas, proselitismo e doutrinação, seja de natureza político-partidária, religiosa ou de outras naturezas. A avaliação pedagógica, por definição de sua própria legislação (Decretos 7.084/2010 e 9.099/2017) não opera com critérios de ordem ideológica previamente estabelecidos, posto que o PNLD não pressupõe a lógica da censura sobre as coleções. Ao lidar com temas do tempo presente, as opções teóricas, metodológicas, 
historiográficas e ideológicas dos autores não são consideradas como elementos a serem interditados, mas como aspectos inerentes à identidade epistemológica da História enquanto campo de conhecimento.

Sob esse ângulo, Choppin (2004, p. 561) alerta que "escrever a história dos livros escolares - ou simplesmente analisar o conteúdo de uma obra - sem levar em conta as regras que o poder político, ou religioso, impõe aos diversos agentes do sistema educativo, quer seja no domínio político, econômico, linguístico, editorial, pedagógico ou financeiro, não faz qualquer sentido". Certeau (2007, p. 66), por sua vez, mostra que "toda pesquisa historiográfica se articula com um lugar de produção sóciohistórico, político e cultural". Miranda e Luca (2004, p. 124) enfatizam que "o livro didático é um produto cultural dotado de alto grau de complexidade e que não deve ser tomado unicamente em função do que contém sob o ponto de vista normativo, uma vez que não só sua produção se vincula a múltiplas possibilidades de didatização do saber histórico, como também sua utilização pode ensejar práticas de leitura muito diversas".

Com base no que está disposto na legislação educacional desde a LDBEN 9394/96, nos resultados das pesquisas no campo do Ensino de História, na abordagem do tema tratado nesse estudo, e considerando os livros didáticos avaliados no âmbito do PNLD 2017, o que se pode requerer da relação entre a ciência de referência (História) e o saber histórico escolar, é que se considerem as bases epistemológicas na construção da narrativa histórica selecionada, para compor a potencialidade do livro didático frente à diversidade e à pluralidade de saberes e versões sobre o passado que advêm dos diferentes grupos sociais. O conhecimento científico é produzido em uma temporalidade específica e também a partir de relações singulares com as pulsões imediatas da sociedade. É fato que a ciência deve responder a essas pulsões, mas tais respostas precisam ser elaboradas a partir de métodos que atestem o alcance e as consequências das mesmas em curto, médio e longo prazo, considerando todos os partícipes da sociedade.

Esse é o quadro referencial a partir do qual o tema eleito para essa investigação - as Jornadas de Junho de 2013 - será analisado. 


\section{O tratamento das Jornadas de Junho de 2013 no Livro Didático de História - PNLD 2017}

Para responder à questão "como o tema das Jornadas de Junho de 2013 é apresentado nos livros didáticos de História do PNLD 2017?", constituiu-se um corpus documental delimitado pelas 19 coleções destinadas aos anos finais do ensino fundamental, inscritas no respectivo processo avaliativo, tomando como recorte os capítulos em que o assunto é abordado nos livros do $9^{\circ}$ ano. Cumpre destacar que, dentre as 19 coleções inscritas, 14 foram aprovadas para compor o Guia de Livros Didáticos e 5 foram reprovadas na etapa da avaliação pedagógica ${ }^{4}$.

Dentre as 19 coleções em análise, o tema das Jornadas de Junho de 2013 é abordado por 15 coleções, no volume destinado ao nono ano, conforme disposto no quadro a seguir:

Quadro 1 - Presença do tema das Jornadas de Junho de 2013 no LDH

\begin{tabular}{|l|l|l|}
\hline \multicolumn{2}{|l|}{ Coleções que tratam do tema (15) } & \multicolumn{2}{|l|}{ Coleções que não tratam do tema } \\
\hline Coleção $1 ;$ Coleção 2; Coleção $3 ;$ & Coleção 4 \\
Coleção $6 ;$ Coleção 7; Coleção 8; & Coleção 5 \\
Coleção 9; Coleção 10; Coleção 11; & Coleção 12 \\
Coleção 13; Coleção 14; Coleção 16; & Coleção 15 \\
Coleção 17; Coleção 18; Coleção 19. & \\
\hline
\end{tabular}

Fonte: Coleções inscritas no PNLD 2017.

Nesse corpus, procurou-se identificar a narrativa historiográfica adotada, as abordagens positivas e negativas atribuídas ao assunto, os materiais que subsidiam o tema no livro do aluno, as propostas de atividades apresentadas aos alunos, e, por fim, as orientações e os materiais destinados aos professores para ancorar o desenvolvimento do tema em sala de aula e para complementação dos seus estudos, conforme

\footnotetext{
${ }^{4}$ As coleções são codificadas em números de 1 a 19, de modo a preservar sua vinculação aos dados apresentados. A lista das coleções inscritas no PNLD 2017 encontra-se discriminada em ordem alfabética ao final do artigo.
} 
disposto no Manual do Professor. A fim de orientar a análise dos dados fornecidos pelo corpus, agrupamos estes indicadores em duas categorias de proposições sobre o assunto em questão, elaboradas pelos livros didáticos: 1) a proposta de narrativa histórica (o modo como é tratado o assunto), por meio dos três primeiros indicadores; 2) a proposta de aprendizagem histórica (porque tratar deste assunto), por meio dos dois indicadores finais. Assim, pretende-se elaborar um quadro global da abordagem concedida ao tema das Jornadas de Junho de 2013 pelos livros didáticos de História.

\section{O livro didático de História e as Jornadas de Junho: a proposta de narrativa histórica}

Antes de adentrar a análise da narrativa elaborada pelos livros didáticos, é necessário expor uma caracterização desse episódio, tarefa que desenvolveremos com base em Medeiros (2014), Scherer-Warren (2014) e Mendonça (2018). A narrativa mais consensual sobre as Jornadas de Junho de 2013 as caracteriza como o conjunto de atos, protestos e ocupações que ocorreu em dezenas de cidades do país ao longo do mês de junho de 2013 e nos meses subsequentes, cujo impulso inicial se deu contra o aumento das tarifas do transporte urbano municipal, capitaneado pelo Movimento Passe Livre (MPL) em São Paulo e a consequente reação repressiva da polícia militar sobre os estudantes. Se a pauta inicial era a revogação dos 20 centavos de aumento da tarifa, logo as razões dos protestos se multiplicaram: desigualdades sociais, cerceamento a direitos, insulamento da esfera política (MENDONÇA, 2018), apoio dos estudantes aos metroviários contra o sucateamento do metrô em São Paulo, manifestações contra a política de pacificação da Rocinha no Rio de Janeiro, baixa qualidade dos serviços públicos, denúncias de corrupção, gastos excessivos com a Copa das Confederações de 2013 e com a Copa do Mundo de Futebol FIFA de 2014, crescimento da inflação e suposto abandono das metas pelo governo federal (MEDEIROS, 2014), dentre outras. Quanto às suas origens, Mendonça (2018, p. 9) afirma:

Não concordamos com o argumento de que as Jornadas foram completamente espontâneas, horizontais e sem base 
em formas anteriores de mobilização. Tampouco as entendemos como resultados de lutas organizadas que foram se ampliando. Percebemos, em tal processo, uma sobreposição entre espontaneidade e organização, que viabiliza sua singularidade e a potencializa. Sobreposição essa que percorre diferentes caminhos em diferentes localidades.

No esforço de dimensionar o fenômeno das Jornadas de Junho de 2013 num espectro interpretativo mais amplo, Medeiros (2014) aponta três principais hipóteses de análise: 1) do ponto de vista dos eventos, as Jornadas de Junho resultaram da combinação do aumento do valor das passagens do transporte municipal no curso do ano letivo de escolas e universidades, com a truculência repressiva da Polícia Militar; 2) do ponto de vista das estruturas, as Jornadas se relacionam com o debate acerca da nova classe média ou nova classe trabalhadora surgida no Brasil pósgoverno Lula; 3) por fim, do ponto de vista da ação coletiva, as Jornadas de Junho podem ser entendidas como um momento de afirmação de novas formas de organização dos movimentos sociais, tomando como base de análise o Movimento Passe Livre de São Paulo, que capitaneou os primeiros protestos.

As Jornadas evidenciaram a presença compartilhada de atores sociais das mais diversas orientações políticas nas ruas, apontando para uma pluralidade de forças sociais. Grandes manifestações com o protagonismo das juventudes não são situações inéditas no Brasil recente, podendo-se citar as mobilizações contra a ditadura, como as Diretas Já, além dos Caras Pintadas e do Movimento pela Ética na Política. Há também manifestações mais regulares, como o Grito dos Excluídos, as Marchas das Margaridas, os movimentos pela Reforma Agrária e pela habitação urbana (MST, MTST), dos atingidos por barragens, movimentos negro, indígena, etc. Segundo Scherer-Warren (2014), uma das especificidades das Jornadas de Junho de 2013 em relação a essas manifestações anteriores é o fato de terem sido convocadas pelas redes sociais virtuais, potencializando a adesão popular e ampliando os locais dos protestos, além de promover vasta visibilidade às ações coletivas. Outro aspecto de diferenciação entre as manifestações da 
segunda metade do século $X X$ e as Jornadas de Junho é que aquelas se articulavam ao redor de uma causa em comum, "com a tendência de se construir uma identificação em torno de um ideário político-ideológico mais unificado" (SCHERER-WARREN, 2014, p. 2), condição que não se reproduziu sem fragmentações e antagonismos nas Jornadas de Junho de 2013. Como vimos, nessa última as motivações são diversas e se espraiam em diferentes grupos sociais, com distintas lideranças, com suas respectivas e variadas pautas de reivindicação.

$\mathrm{Na}$ análise dos conteúdos dispostos nas 15 coleções que abordam o tema, identifica-se que a caracterização dos eventos ocorridos é pautada em fontes jornalísticas, fazendo uso de informações e análises expostas na grande mídia impressa, notadamente jornais e revistas de grande circulação, lançando mão, também, de entrevistas com estudiosos e formadores de opinião (sociólogos, cientistas políticos, jornalistas) que analisam os eventos no calor da hora, sem distanciamento temporal. Temse, então, uma narrativa de cunho predominantemente sociológico e/ou jornalístico, com proeminência das reivindicações políticas e econômicas dos movimentos e atores que ocuparam as ruas. $O$ tom da narrativa se aproximaria, assim, do entendimento de Chauveau e Tétart (1999) sobre o que caracterizaria uma História imediata.

As causas que originaram as manifestações são destacadas como: o aumento das tarifas de transporte; protestos da população que refletiam a insatisfação dos milhões de brasileiros em relação à educação, saúde, segurança e transporte; insatisfação com os vultosos gastos para sediar a Copa do Mundo de Futebol de 2014; contra a possibilidade de redução do poder do Ministério Público na Proposta de Emenda Constitucional 37/2011 ; desaceleração econômica; violenta repressão policial contra as passeatas; pelo protagonismo dos cidadãos na política brasileira; combate à

\footnotetext{
${ }^{5}$ A PEC 37/2011 sugeria incluir um novo parágrafo ao Artigo 144 da Constituição Federal, que trata da Segurança Pública. Uma vez aprovada, essa regra concederia o poder de investigação criminal exclusivamente às polícias federal e civil, retirando tal atribuição de alguns órgãos e, sobretudo, do Ministério Público. Como reação à proposta, diversas organizações lançaram a campanha "Brasil contra a impunidade". O Plenário da Câmara dos Deputados rejeitou a PEC 37 no dia 25/06/2013, por 430 votos a 9 e 2 abstenções.
} 
corrupção em todas as esferas de governo, dentre outros fatores de menor evidência. Em algumas obras didáticas elabora-se contundente crítica ao governo da então presidente Dilma Rousseff.

$\mathrm{Na}$ abordagem do tema, todos os materiais destacam que as manifestações das Jornadas de Junho de 2013 foram iniciadas contra o aumento das tarifas de transporte público, mas posteriormente se espalharam por todo o país, como se destaca no exemplo a seguir:

Em 2013, protestos iniciados em São Paulo se transformaram em uma onda gigante de manifestações que se espalhou pelo país todo. No dia 17 de junho aconteceram protestos em várias capitais e na Esplanada dos Ministérios, em Brasília (Coleção 6, v. 9, p. 318).

Os materiais também ressaltam que, na medida em que esses protestos foram tomando maiores proporções, os motivos das manifestações também foram se alargando e se tornando mais difusos, tendo como exemplo os protestos contra os gastos exorbitantes do governo federal para sediar a Copa do Mundo de Futebol FIFA 2014 diante dos problemas crônicos e das condições estruturais precárias do país em saúde, educação, segurança - principalmente após as graves denúncias de corrupção por parte dos representantes políticos em todas as esferas de governo e do mau uso do dinheiro público. Seguem-se situações exemplares de tal narrativa:

Com o crescimento do movimento, os manifestantes aprofundaram suas reivindicações, passando a criticar os baixos investimentos em Saúde e Educação, a violência policial, a corrupção, e os gastos governamentais com a Copa do Mundo. Os manifestantes propunham, entre outras coisas, a "democratização da política". Segundo estudiosos, os protestos populares de junho de 2013 no Brasil apresentaram algumas características importantes, que listamos a seguir: a) a ausência de grandes partidos e sindicatos; b) o uso intensivo de redes sociais na mobilização e organização dos protestos; c) a presença significativa de um grande número de jovens entre os manifestantes, quebrando o mito do desinteresse da juventude pela política; d) a capacidade de esses movimentos reunirem pessoas de diferentes camadas sociais (Coleção 6, v. 9, p. 319).

Em 2013, um movimento iniciado nas principais cidades brasileiras em protesto contra o aumento das passagens do transporte coletivo logo se transformou em manifestações 
contra governadores, prefeitos e também contra o governo federal. As Jornadas de Junho, como ficaram conhecidas, se espalharam pelo país e incorporaram reivindicações mais gerais, como a melhoria na educação e na saúde públicas, o fim da corrupção e a redução dos gastos do governo com obras para a realização da Copa do Mundo (2014) e das Olimpíadas (2016) (Coleção 16, v. 9, p. 248).

As manifestações de junho de 2013 denotam que parte da sociedade brasileira não está satisfeita com os serviços transportes, saúde e educação -, bem como exige uma postura mais ética da classe política. O combate à corrupção tem ecoado em todas as manifestações populares recentes (Coleção 13, v. 9, p. 358).

Com as mudanças no rumo das manifestações, que partem da rejeição ao aumento das tarifas de transporte público e desembocam no combate à corrupção, outro ponto de destaque nos livros didáticos são as reivindicações populares contra a diminuição do poder de investigação do Ministério Público na Proposta de Emenda Constitucional 37/2011. São narrativas semelhantes à destacada na sequência:

Em meados de 2013, manifestações populares em várias cidades do país criticaram os gastos públicos nas obras feitas para o país sediar a Copa do Mundo Fifa 2014. Os protestos iniciaram contra o aumento das tarifas de transporte público e aglutinaram reivindicações pela qualidade na saúde e educação públicas e pela manutenção do poder de investigação do Ministério Público (ameaçado de ser extinto caso o Projeto de Emenda Constitucional 37 fosse aprovado pelos parlamentares, o que não aconteceu) (Coleção 2, v. 9, p. 275).

$\mathrm{Na}$ relação entre as questões econômicas e as manifestações de junho de 2013, há associações sobre os indicadores econômicos e os problemas apresentados desde 2012, mostrando a insatisfação de grande parte da população brasileira, como, por exemplo:

[...] o desequilíbrio da balança comercial (aumento das importações e a diminuição das exportações), o aumento da taxa de juros e a diminuição da competitividade das empresas brasileiras [...] (Coleção 18, v. 9, p. 264).

Outro aspecto de destaque nos livros didáticos é a violência policial contra as manifestações. Essas ações são apresentadas da seguinte maneira:

História \& Ensino, Londrina, v. 24, n.2, p.163-195, jul./dez. 2018 
Em junho de 2013, na cidade de São Paulo, manifestantes protestaram contra o aumento das passagens do transporte público. A violência policial contra os manifestantes gerou ondas de protestos em todo o país. Milhares de pessoas tomaram as ruas das grandes capitais protestando não apenas contra o aumento das passagens, mas contra a má qualidade dos serviços públicos, a corrupção, entre outras reivindicações (Coleção 11, v. 9, p. 313).

Os jovens foram duramente reprimidos pela Polícia Militar. A imprensa e as redes sociais difundiram as imagens da violência exagerada, o que provocou a indignação de muitos setores sociais. O MPL organizou novos atos públicos, e milhares de pessoas pararam as principais avenidas das grandes capitais, forçando os governos a manter o valor das tarifas (Coleção 19, v. 9, p. 239).

Também recebe atenção, em algumas coleções, o protagonismo das pessoas, abordagem destacada no exemplo a seguir:

Após quase 30 anos do movimento Diretas Já e pouco mais de 20 anos após o movimento pelo impeachment de Collor, o Brasil assistiu a uma nova mobilização tão grande quanto aquelas. Ao longo do mês de junho de 2013, milhares de pessoas se reuniram nas ruas, em diferentes cidades brasileiras. O auge das manifestações ocorreu no dia 20 de junho: 1,5 milhão de pessoas se apresentaram nas ruas de 69 cidades. Se em 1984 a pauta política era clara e bem objetiva [...], em 2013 a pauta era bastante difusa. O estopim das mobilizações foi o aumento de 20 centavos da tarifa do transporte público na cidade de São Paulo, mas, ao longo do mês, os manifestantes passaram a protestar, entre outras coisas, contra 0 ambiente político brasileiro, principalmente contra a corrupção; contra os gastos excessivos com a Copa do Mundo; em favor de melhorias nas áreas de saúde, educação e segurança pública. Também colocaram em pauta a luta por direitos indígenas e contra o preconceito e o racismo. O movimento era apartidário, não tinha líderes definidos e começou com a mobilização de estudantes, a maioria jovens entre 14 e 24 anos, segundo pesquisas do Ibope. Contou com auxílio das redes sociais para organizar e divulgar as ações no território brasileiro. A reação violenta das polícias contra manifestantes e também jornalistas revelou uma face repressora e problemática das forças de segurança. O uso de leis que remetiam ao período da ditadura, em plena vigência da Constituição de 1988 e de seus valores democráticos, expressou uma série de contradições da sociedade brasileira. Nas ruas, as pessoas se tornaram protagonistas da política brasileira. Depois de 2013, são frequentes os protestos e isso é uma novidade na sociedade brasileira, que parecia estar em "adormecimento" desde a campanha pelas Diretas Já e do movimento pelo 
impeachment do ex-presidente Collor (Coleção 7, v. 9, p. 225).

Os livros didáticos trazem, ainda, em sua narrativa, diferentes interpretações a respeito da amplitude dos acontecimentos que abarcam as chamadas Jornadas de Junho como um processo histórico, atribuindo aspectos positivos e negativos ao seu contexto.

\title{
Quadro 2 - Abordagens positivas e negativas atribuídas às Jornadas de Junho
}

\author{
de 2013
}

\begin{tabular}{|c|c|}
\hline Aspectos positivos apontados & Aspectos negativos apontados \\
\hline $\begin{array}{l}\text { Os pontos positivos foram: em resposta às } \\
\text { pressões das ruas, foi criado o programa Mais } \\
\text { Médicos, que prevê investimentos em hospitais e } \\
\text { unidades de saúde e a contratação de médicos } \\
\text { para regiões onde há carência desses } \\
\text { profissionais, como a periferia de grandes cidades } \\
\text { e municípios localizados em áreas remotas do } \\
\text { território nacional (Coleção } 2 \text {, p. } 275 \text { ). } \\
\text { No que tange aos pontos positivos, uma das } \\
\text { vitórias foi a revogação das tarifas do transporte } \\
\text { público em algumas cidades brasileiras (Coleção } \\
3, \text { p. 355). } \\
\text { Em julho de } 2013 \text {, Dilma lançou o Programa Mais } \\
\text { Médicos que [...] facilitou a chegada de médicos } \\
\text { estrangeiros para trabalhar em postos de saúde } \\
\text { de cidades pequenas durante três anos. [...] Em } \\
\text { setembro de 2013, após a aprovação do } \\
\text { Parlamento, Dilma assinou a importante Lei que } \\
\text { destina 75\% dos royalties da exploração do } \\
\text { petróleo e do gás natural para a Educação e os } \\
25 \% \text { restantes para a Saúde (Coleção } 6 \text {, p. 319). } \\
\text { Como resposta, o governo anunciou algumas } \\
\text { medidas, como o programa "Mais Médicos", que } \\
\text { trouxe profissionais do exterior para atender à } \\
\text { população de pequenos municípios e áreas } \\
\text { periféricas (p. 222). Nas ruas, as pessoas se } \\
\text { tornaram protagonistas da política brasileira. } \\
\text { Depois de } 2013, \text { são frequentes os protestos e } \\
\text { isso é uma novidade na sociedade brasileira, que } \\
\text { parecia estar em "adormecimento" desde a } \\
\text { campanha pelas Diretas Já e do movimento pelo } \\
\text { impeachment do ex-presidente Collor (p. 225) } \\
\text { (Coleção } 7, \text { p. } 222 \text { e } 225 \text { )". } \\
\text { Alguns avanços vêm se consolidando desde o } \\
\text { retorno à democracia, em } 1985: \text { o controle da } \\
\text { inflação gerou uma relativa estabilidade } \\
\text { financeira, que relativa estabilidade financeira, }\end{array}$ & $\begin{array}{l}\text { Em 2013, Dilma ostentava alta popularidade, } \\
\text { mas em junho desse ano manifestações políticas } \\
\text { tomaram as ruas das principais cidades do país. } \\
\text { Durante a Copa das Confederações, evento que } \\
\text { antecedia a realização da Copa do Mundo de } \\
\text { Futebol de 2014, a população foi às ruas e } \\
\text { criticou os altos custos dos eventos esportivos, } \\
\text { denunciando a precariedade dos serviços } \\
\text { públicos (Coleção 7, p. 222). } \\
\text { A reação violenta das polícias contra } \\
\text { manifestantes e também jornalistas revelou uma } \\
\text { face repressora e problemática das forças de } \\
\text { segurança. O uso de leis que remetiam ao } \\
\text { período da ditadura, em plena vigência da } \\
\text { Constituição de 1988 e de seus valores } \\
\text { democráticos, expressou uma série de } \\
\text { contradições da sociedade brasileira (Coleção } 7 \text {, } \\
\text { p. } 225 \text { ). } \\
\text { Entretanto, é preciso atingir algumas metas: } \\
\text { reduzir a desigualdade; erradicar a pobreza e a } \\
\text { miséria; zerar o analfabetismo; melhorar os } \\
\text { índices de educação; defender e garantir os } \\
\text { direitos dos povos indígenas; realizar reforma } \\
\text { agrária, reforma política e reforma tributária; } \\
\text { estimular o desenvolvimento tecnológico e } \\
\text { científico; erradicar a corrupção; proporcionar } \\
\text { saúde pública de qualidade para todos; } \\
\text { aumentar e melhorar a malha viária; investir na } \\
\text { preservação ambiental; desenvolver políticas } \\
\text { públicas eficientes em todas as áreas; pôr fim à } \\
\text { violência em todas as instâncias; e acabar com o } \\
\text { trabalho infantil. Enfim, resolver os problemas } \\
\text { históricos que violam os direitos humanos dos } \\
\text { cidadãos (Coleção } 13, \text { p. } 358 \text { ). } \\
\text { Os manifestantes alegavam que, enquanto o } \\
\text { governo gastava bilhões de reais em obras } \\
\text { voltadas à Copa do Mundo de 2014 e aos Jogos } \\
\text { Olímpicos de 2016, muitas delas sem trazer }\end{array}$ \\
\hline
\end{tabular}

História \& Ensino, Londrina, v. 24, n.2, p.163-195, jul./dez. 2018 
que permitiu maior acesso a bens de consumo, inclusive para as classes menos favorecidas; alguns serviços essenciais, como saneamento básico, energia elétrica e coleta de lixo, foram estendidos a um número maior de brasileiros. Mas ainda não atendem a todos nem de maneira satisfatória; a educação tem sido ampliada em vários programas de governo. O Ensino Fundamental, por exemplo, passou a ter nove anos (Coleção 13, p. 357).

Outro destaque do governo Dilma foi a aprovação no Congresso Nacional da Comissão Nacional da Verdade, formada para investigar as violações dos direitos humanos ocorridas entre 18 de setembro de 1946 e 5 de outubro de 1988, especialmente no período do regime militar (1964-1985). O relatório final da comissão, divulgado no final de 2014, pedia a punição de mais de 300 agentes ligados às graves violações dos direitos humanos (Coleção 10, p. 319).

O MPL organizou novos atos públicos, e milhares de pessoas pararam as principais avenidas das grandes capitais, forçando o governo a manter o valor das tarifas. [...] Novas manifestações em 2015, sem o mesmo tamanho de mobilização: [...]. Mas o MPL demonstrou a força das centenas de pequenas organizações de jovens das periferias, os chamados coletivos, que lutam por direitos sociais e econômicos (Coleção 19, p. 286).

\section{Fonte: Coleções inscritas no PNLD 2017.}

benefícios permanentes, a população brasileira continuava sofrendo com um transporte coletivo de baixa qualidade, que encarece ano após ano. Apesar do desgaste da imagem do governo, as eleições de 2014 Dilma Rousseff derrotou, no segundo turno e por uma diferença apertada de votos, o candidato Aécio Neves, do PSDB, e foi eleita para um novo mandato (Coleção 14, p. 260).

Na área da política, a necessidade de compor um governo de coalizão que lhe desse apoio no Congresso Nacional (Assembleia e Senado) levou a presidente a dividir ministérios e secretarias com os partidos aliados, sobretudo o PMDB. Isso lhe trouxe dificuldades, especialmente entre os congressistas, que exigiam verbas e cargos em trocas da aprovação de projetos. Escândalos, acusações de corrupção e interesses partidários provocaram uma troca relativamente frequente de ministros e de altos funcionários da administração pública. Em tal quadro, o descontentamento popular ganhou enorme impulso em 2013 diante das dificuldades (municipal, estadual e federal) em lidar com as demandas cotidianas da população. Tendo como estopim as necessidades ligadas ao transporte público, somadas aos elevados gastos com as construções e os preparativos para a Copa do Mundo de Futebol de 2014, uma série de manifestações se espalharam pelo Brasil em junho de 2013, numa onda de protestos conhecida como manifestações de junho de 2013 (Coleção 10, p. 318).

As passeatas são descritas como bastante violentas quanto aos confrontos entre manifestantes e policiais. Também, como aspecto que pode ser negativo, as vaias à presidenta na abertura da Copa do Mundo [...] Em março de 2013, a avaliação positiva do governo chegava a $65 \%$. Ao final de junho, após as manifestações, 0 índice despencava para 30\%. (Coleção 17, p. 303-304).

\section{No quadro precedente procuramos sistematizar alguns dos}

principais elementos do contexto e os efeitos produzidos pelas Jornadas de Junho sobre as ações do poder público e da sociedade civil, de acordo com a narrativa dos livros didáticos analisados. Na primeira coluna constam alguns dos efeitos positivos alcançados, ou seja, conquistas e avanços que são atribuídos, em alguma medida, a esse movimento coletivo, como, por exemplo: a revogação do aumento das tarifas do transporte público em 
algumas cidades; a criação do Programa Mais Médicos, em resposta às demandas por melhores condições de atendimento à saúde; a assinatura da Lei que destina os royalties da exploração do petróleo e do gás natural para a Educação e para a Saúde; a demonstração de força e organização das juventudes, sob a liderança do $\mathrm{MPL}$, na luta por direitos sociais $\mathrm{e}$ econômicos.

$\mathrm{Na}$ segunda coluna buscamos demonstrar como os livros didáticos anunciam os aspectos negativos das Jornadas, destacando, em especial, os descontentamentos dos manifestantes e os custos políticos das manifestações para o governo de Dilma Rousseff, a saber: críticas aos altos investimentos do governo nos eventos esportivos de 2014 e 2016 (Copa do Mundo e Olimpíadas), frente à precariedade dos serviços públicos prestados à população; reação violenta das forças de segurança contra manifestantes e jornalistas; as denúncias de corrupção, instabilidades na estrutura administrativa e interesses partidários sobrepostos aos interesses da nação; a queda nos índices de popularidade da presidente Dilma Rousseff e as consequentes vaias que sofria em pronunciamentos e aparições públicas. Pode-se verificar, nessas diversas narrativas, que há um esforço das autorias dos livros didáticos de compor um cenário diverso, com a concorrência de diferentes pontos de vista.

A narrativa apresentada aos alunos sobre o conteúdo Jornadas de Junho de 2013 recebe suporte quase que exclusivamente de imagens, com exceção da indicação de uma leitura complementar. Explica-se a ausência de outros materiais por se tratar de um tema recente a respeito do qual não se dispunha de uma efetiva produção historiográfica. Ao todo, identificaram-se 19 imagens dispostas no conjunto das coleções. Seguem exemplos de algumas imagens encontradas: 
Quadro 3 - Imagens alusivas às Jornadas de Junho de 2013 - PNLD 2017

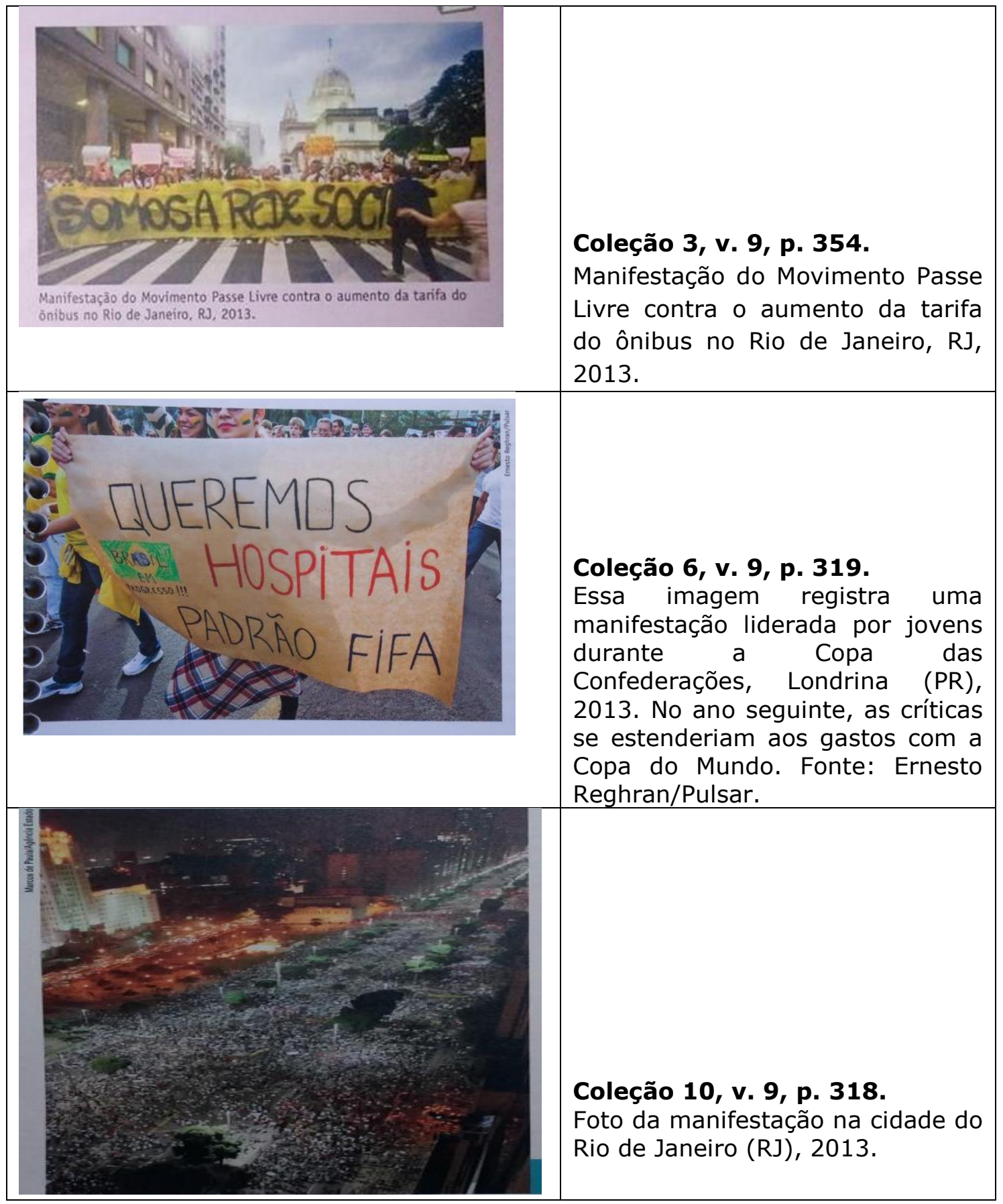




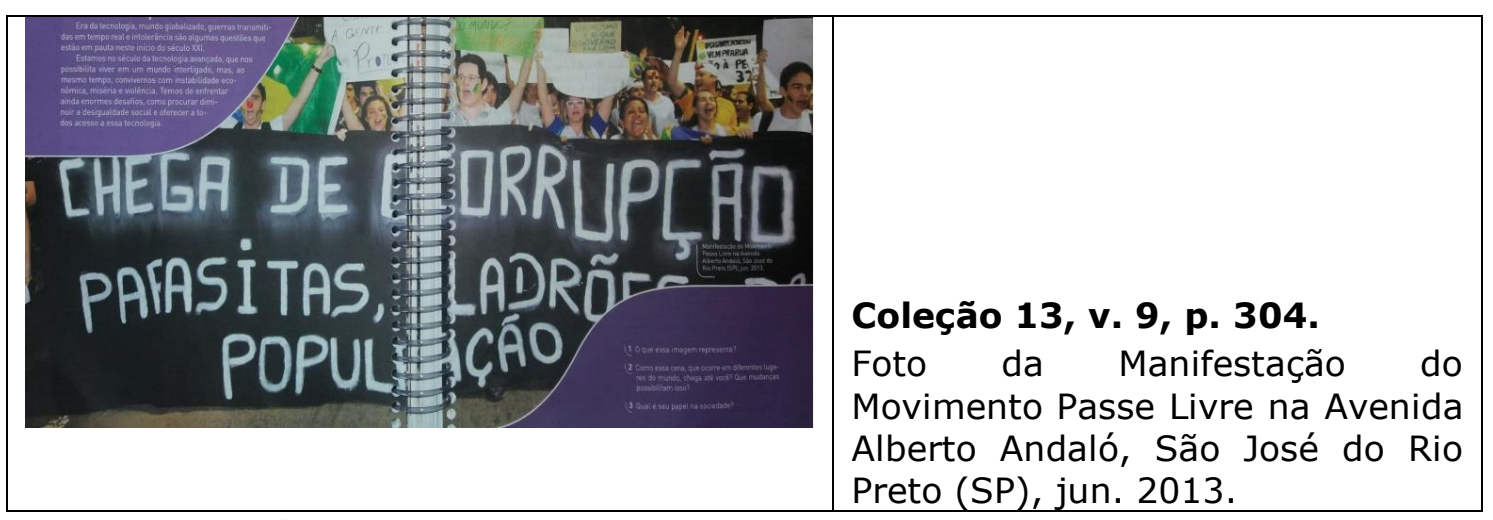

Fonte: Coleções inscritas no PNLD 2017.

Diante dos exemplos de construção narrativa e do suporte imagético veiculados pelos livros didáticos de História, percebe-se a presença de pluralidade interpretativa acerca das motivações, causas, agentes e instituições envolvidos ao tematizar as Jornadas de Junho de 2013, enfatizando diferentes questões dos âmbitos político e econômico, abordando as demandas sociais e adensando a historicidade do processo, ao promover comparações e problematizar as diversas instâncias implicadas nos atos dos manifestantes. Nos livros analisados, o movimento denominado Jornadas de Junho de 2013 recebe tratamento positivado ao enunciar como possíveis resultados de tais manifestações a efetivação de ações concretas, por parte do governo, para os problemas estruturais do país (Programa Mais Médicos, ampliação das verbas para a educação e controle da inflação); vitória da revogação do aumento das tarifas de transporte; exercício da cidadania e preocupação com o direcionamento dos gastos de dinheiro público.

Por outro lado, a abordagem sobre o tema segue o viés negativo no estabelecimento de críticas aos gastos exorbitantes com a Copa do Mundo de Futebol; escândalos de corrupção e repressão policial violenta contra as manifestações. Conclui-se que a narrativa apresentada nos livros traz uma diversidade de perspectivas dos desdobramentos das Jornadas de Junho de 2013, contribuindo para que os alunos se posicionem criticamente diante dos fatos recentes.

Ao aproximarmos o esforço de produção de uma narrativa que possa conferir inteligibilidade para um período tão recente da História do Brasil às 
motivações teórico-metodológicas da História do tempo presente, entendemos que o livro didático de História tanto busca criar contingências de compreensão da realidade (DELGADO; FERREIRA, 2013), quanto filia-se às condições da operação histórica que lida com o presente, ao procurar combater - ainda que por meio de descrições e do apelo às fontes jornalísticas - o que Rioux (1999) entende por atemporalidade contemporânea, a experiência de suspensão do tempo presente despido de seu devir histórico. O livro didático cumpre, neste sentido, papel de vetor, nos ambientes escolares, de interpretação de um passado recente que muitas vezes se perde em um presente a-histórico, simplesmente porque o entende como objeto.

Embora a construção narrativa das Jornadas de Junho nos livros didáticos seja majoritariamente descritiva, não se afasta drasticamente das interpretações produzidas posteriormente (MEDEIROS, 2014; SCHERERWARREN, 2014; MENDONÇA, 2018) - mesmo estas ainda estão imbricadas em uma temporalidade muito próxima à dos acontecimentos de 2013 e articulam-se em hipóteses e na condição de provisoriedade explicativa condição enfrentada por qualquer explicação histórica. As autorias dos livros didáticos de História parecem estar conscientes desta condição, ao tomarem para si a responsabilidade de fornecer algum tipo de resposta à pulsão da história escolar acerca de eventos marcantes da História imediata do país demonstrado, especialmente, na utilização máxima dos materiais disponíveis: coberturas jornalísticas, fotografias, artigos de opinião - e, mesmo em sua complexidade produtiva, enfrentar o desafio de narrar um processo de acontecimentos de difícil demarcação, com efeitos que extrapolam a ambição interpretativa. Se, por fim, perguntássemos às coleções que produziram narrativas de forma responsável - considerando diferentes âmbitos de visualização e agência históricas -, se é possível fazer e dizer sobre a História do tempo presente nos livros didáticos, a resposta seria sim - de acordo com o que que se pode dizer nos limites de análises dessa natureza. 


\section{4. [O que] É possível aprender com o tempo presente: as Jornadas de Junho nos livros didáticos de História}

Nesta seção apresentamos as atividades propostas aos estudantes acerca do tema das Jornadas de Junho de 2013 e as orientações que constam no Manual do Professor. Partimos do pressuposto de que, ao incluir exercícios que problematizam a temática em questão e orientar os professores sobre como tratar do tema, as autorias dos livros didáticos de História entendem que é possível aprender por meio da História do tempo presente.

$\mathrm{Na}$ sistematização e interpretação dos acontecimentos das Jornadas de Junho de 2013, dentre os 15 que optaram por trabalhar com o tema, oito livros didáticos apresentam propostas para um estudo mais aprofundado da questão. A respeito da presença de orientações específicas para o professor quanto ao desenvolvimento do tema em sala de aula, são nove livros, dentre os 15 do corpus, que as contemplam.

\section{As propostas de atividades abordando o tema}

As atividades foram elencadas segundo as seguintes tipologias: tarefas que solicitam análises e posicionamentos dos alunos sobre as questões em maior destaque no período; comparação entre os diferentes períodos da História do país; análise de filmes, documentários e leituras de textos; análise de fotos e fatos; questões opinativas (grande maioria no campo da construção de hipóteses para o futuro das manifestações e do país) e identificação dos movimentos. Nas propostas metodológicas para interpretar esses acontecimentos, as autorias recorrem às seguintes estratégias didáticas: levantamento de conhecimentos prévios, debates, opiniões, leituras de imagens e identificação das características do movimento das Jornadas de Junho de 2013, dentre outras. 
Quadro 4 - Propostas de atividades para os alunos

\begin{tabular}{|l|l|}
\hline \multicolumn{1}{|c|}{ Tipologias } & \multicolumn{1}{|c|}{ Coleções } \\
\hline $\begin{array}{l}\text { Atividades que solicitam análises e posicionamento } \\
\text { dos alunos sobre as questões em maior destaque no } \\
\text { período. }\end{array}$ & $\begin{array}{l}\text { Coleção 6 } \\
\text { Coleção 7 } \\
\text { Coleção 10 } \\
\text { Coleção 11 } \\
\text { Coleção 13 }\end{array}$ \\
\hline $\begin{array}{l}\text { Comparação entre os diferentes períodos da História } \\
\text { do país. }\end{array}$ & $\begin{array}{l}\text { Coleção 7 } \\
\text { Coleção 8 } \\
\text { Coleção 10 }\end{array}$ \\
\hline Assistir filmes, documentários e leituras de textos. & $\begin{array}{l}\text { Coleção 3 } \\
\text { Coleção 10 } \\
\text { Coleção 13 }\end{array}$ \\
\hline Análise de fotos e fatos. & $\begin{array}{l}\text { Coleção 10 } \\
\text { Coleção 13 }\end{array}$ \\
\hline $\begin{array}{l}\text { Questões opinativas (grande maioria no campo da } \\
\text { construção de hipóteses para o futuro). }\end{array}$ & Coleção 3 \\
\hline Coleção 10 \\
\hline Identificação dos movimentos. & Coleção 10 \\
Coleção 19
\end{tabular}

Fonte: Coleções inscritas no PNLD 2017.

Na tipologia de atividades que solicitam análises e posicionamentos dos alunos sobre as questões de maior destaque no período, consta proposições dessa natureza:

A copa do Mundo de 2014 foi avaliada de forma diversa. Para o governo e parte da população, a Copa foi um sucesso, pois transcorreu sem maiores problemas e atraiu um grande número de turistas. Já para a oposição e outra parte da população, os altos gastos com a sua realização e o atraso na entrega das obras de mobilidade urbana justificam dizer que foi prejudicial ao país. E você, o que pensa sobre o assunto? Justifique. (Coleção 6, v. 9, p. 320).

Avalie mudanças que possam ter ocorrido na História do Brasil no tempo atual. Você avalia essas mudanças de maneira positiva ou negativa? Projetos sociais do governo beneficiaram você e sua família? Você tem participado de movimentos sociais ou de mobilizações de protestos? Afinal, como você tem vivido a História do seu tempo presente? (Coleção 11, v. 9, p. 313).

Na tipologia "comparação entre os diferentes períodos da História do país" há propostas que solicitam aos estudantes refletirem sobre a seguinte pergunta "Você já pensou sobre como será a sua vida e a dos brasileiros nas próximas décadas?" (Coleção 10, p. 300). Ainda nessa categoria, constam exemplos de atividades que promovem a relação entre o 
movimento das "Diretas Já" e as Jornadas de junho de 2013, solicitando aos alunos que respondam:

1. Apresente as principais diferenças entre a campanha pelas Diretas Já e os protestos de junho de 2013.

2. Por que os protestos de junho de 2013 significaram uma novidade no contexto brasileiro atual?

3. Discuta com os colegas a importância das manifestações de rua para a prática da democracia (Coleção 7, v. 9, p. 225).

$\mathrm{Na}$ Coleção 3 consta a sugestão para que os alunos assistam ao documentário "Junho: o mês que abalou o Brasil. Brasil, 2014, 72 min. Direção: João Wainer". Este vídeo foi produzido pelo diretor da TV Folha, João Wainer, e conta em perspectiva cronológica, com imagens documentadas, como foram os dias de protesto que consubstanciam as chamadas Jornadas de Junho. O documentário também apresenta depoimentos de representantes dos principais movimentos atuantes (como o Movimento Passe Livre e o Ninja), comandantes da PM, sociólogos, historiadores, filósofos, psicanalistas e jornalistas que participaram da cobertura.

Quanto às propostas envolvendo análise de fotos e o fato, na Coleção 13 há uma grande imagem dividida em duas páginas sobre a Manifestação do Movimento Passe Livre, na Avenida Alberto Andaló, em São José do Rio Preto (SP), em junho de 2013 (p. 303), e solicita-se que os alunos reflitam sobre as seguintes questões:

1. O que essa imagem representa?

2. Como essa cena, que ocorre em diferentes lugares do mundo, chega até você? Que mudanças possibilitam isso?

3.Qual é o seu papel na sociedade? (Coleção 13, v. 9, p. 303)

A partir disso, a reflexão segue baseada nas questões da globalização, dos avanços tecnológicos e da intolerância que marcam o início do século XXI. Nessa coleção, o tema é retomado ao tratar dos "Rumos do Brasil contemporâneo" (p. 358), em um texto baseado no Censo Brasil de 2010 (IBGE), analisando os avanços e os desafios da atualidade: erradicar a miséria e diminuir a igualdade. Em seguida há um poema "O 
outro Brasil que vem aí", de Gilberto Freyre, e uma série de questões interpretativas:

1. Qual era o Brasil almejado por Gilberto Freyre nesse texto, escrito em 1926?

2. O Brasil corresponde ao imaginado ou sonhado por Freyre? Explique.

3. Qual é seu papel na sociedade para que se possa construir esse Brasil?

4. Explique a afirmação do autor de que qualquer brasileiro pode governar o país contanto que seja digno do governo.

5. Analise sua resposta à questão anterior, e explique o que você precisa fazer para colaborar com essa mudança e exercer sua cidadania plenamente, ou seja, exigindo os direitos e cumprindo os deveres? (Coleção 13, v. 9, p. 358).

Ainda nessa tipologia a Coleção 10 propõe que os estudantes analisem a imagem de Manifestantes em Londrina, Paraná, pedindo a intervenção militar no governo federal em 2015 (p. 302), para refletirem sobre as seguintes questões:

1. O que elas representam?

2. As fotos confirmam que o Brasil é um país democrático? Como você justificaria isso?

3. No que as duas imagens se assemelham e no que diferem? (Coleção 10, v. 9, p. 302).

$\mathrm{Na}$ tipologia "questões opinativas", em sua maioria, constam propostas de construção de hipóteses para o futuro, conforme o exemplo da Coleção 10, em que há um breve texto informativo sobre as condições sociais, políticas e históricas que culminaram nas Jornadas. Em seguida, há várias perguntas interpretativas sobre o governo de Dilma Rousseff, a partir das quais os alunos devem debater mais especificamente sobre o tema:

Como impulsionar a economia diante do novo cenário econômico internacional?

As políticas sociais desenvolvidas nos anos anteriores seriam ampliadas ou contidas?

A presidente conseguiria aprovar a Reforma Política?

Como estancar a corrupção espalhada pelo país e qual seria o desdobramento dos escândalos investigados, entre eles o escândalo da Petrobrás e a Operação Lava Jato? (Coleção 10, v. 9 , p. 319).

Na tipologia "identificação dos movimentos", a Coleção 19 apresenta um conjunto de questões em que os estudantes devem interpretar, a partir 
do texto principal, como as manifestações se organizaram em 2013 ( $p$. 291). Em seguida, há um trabalho de análise do texto sobre os "Princípios organizativos do Movimento Passe Livre Nacional". As questões solicitam que os estudantes identifiquem o funcionamento do Movimento, seu principal debate, perspectivas e, ainda, emitam opinião sobre a importância do movimento.

Já na Coleção 10 há uma atividade (p. 320) em que os alunos devem descrever, brevemente, as manifestações das Jornadas de Junho de 2013, com base nos seguintes apontamentos para relatar uma manifestação popular:

\footnotetext{
Situe a manifestação no tempo (data) e no espaço (local). Cite a origem dos manifestantes (a que camadas ou setores da população pertencem).

Indique o contexto histórico em que se deu a manifestação.

Explique quais eram as reivindicações dos manifestantes (Coleção 10, v. 9, p. 320).
}

Dessa maneira, as atividades sugeridas para os alunos analisarem as Jornadas de Junho de 2013 propõem, em sua maioria, situações que envolvem o debate e a expressão dos argumentos opinativos dos alunos de forma oral, sempre fazendo com que os estudantes justifiquem as suas respostas com base na narrativa dos acontecimentos.

\section{Orientações no Manual do Professor}

Há orientações aos professores para que levem "os estudantes a perceberem que estão vivendo a História do Tempo Presente, mesmo que eles não tenham consciência disso". É salientado, também, que "essa é uma atividade importante para refletir sobre o fato de que somos sujeitos históricos" (Coleção 11, MP v. 9, p. 436). Outras orientações são no sentido de incentivar os alunos a estabelecerem relações com contextos diversos, como indica o exemplo a seguir:

Eles (os alunos) podem elaborar associações entre manifestações populares recentes. Podem retomar o Occupy Wall Street, nos EUA, analisar as manifestações brasileiras e pesquisar o caso dos estudantes de Hong Kong, que lutaram por mais liberdade política em relação à China. [...] Cada caso apresenta suas particularidades, que devem ser

História \& Ensino, Londrina, v. 24, n.2, p.163-195, jul./dez. 2018 
ressaltadas pelos alunos, mas também pontos em comum, que os ligam aos outros movimentos mencionados no texto. A intenção da atividade é mostrar os diferentes graus de insatisfação popular ao redor do mundo e salientar as formas de organização social encontradas pelos manifestantes. Os alunos devem perceber que, por meio da organização coletiva é possível fazer valer as reivindicações e, assim, mudar os rumos de um país. (Coleção 3, MP v. 9, p. 505).

Algumas orientações objetivam auxiliar o professor quanto à condução dos diálogos em sala de aula para que os alunos compreendam a "importância das manifestações públicas como demonstração da vontade popular, enfatizando a necessidade de serem organizadas e pacíficas" (Coleção 7, MP v. 9, p. 357).

Registram-se, ainda, orientações relacionadas à importância dos movimentos sociais e ao cenário político no qual as Jornadas de Junho de 2013 se efetivaram, como disposto na sequência:

\begin{abstract}
Professor(a), de 2013 até 2015 pelo menos, movimentos sociais vêm demonstrando insatisfações mais variadas diante dos rumos do governo petista e das reformas de maneira geral. Contudo, é importante destacar com os alunos os diferentes matizes desses movimentos, uma vez que eles se distinguem bastante em termos de reivindicações de direita ou de esquerda. [...]. Dessa forma, abordar a questão dos movimentos sociais na atualidade, destacando suas nuances e divergências, pode ser uma excelente maneira de destacar com os alunos os diferentes interesses desses movimentos, apresentando-Ihes suas demandas e fundamentação históricas para tais. [...] Professor(a), sugerimos abaixo a consulta dos sites de dois movimentos antagônicos que organizam passeatas e protestos no Brasil atualmente: 0 Movimento Passe Livre - MPL - e o Movimento Brasil Livre MBL. Analise o conteúdo com os alunos, em prol de observarem os diferentes tons dos discursos dos dois grupos políticos. É importante que, ao final da análise e da discussão, os alunos tenham uma opinião mais ou menos formada e bem fundamentada sobre a questão dos movimentos políticos no Brasil atual, uma vez que, eventualmente, eles serão chamados para algumas de suas movimentações, ou terão de emitir algum tipo de opinião (Coleção 19, MP v. 9, p. 286-287).
\end{abstract}

Podemos visualizar, tanto nas propostas de atividades quanto nas orientações ao professor, semelhança entre as intenções que regem a História do tempo presente como operação histórico-historiográfica e as de 
aprendizagem histórica, apresentadas pelos livros didáticos, no sentido em que ambos procuram articular, tomando os recursos disponíveis, elementos do presente, adensando-o e localizando-o em perspectiva histórica.

No caso das Jornadas de Junho, que cumprem os requisitos de peculiaridade da História do tempo presente, anunciados por Fico (2012) processos imbricados politicamente, de forte apelo social, em uma temporalidade estendida -, as propostas de aprendizagem histórica do livro didático incluem interpretação, tomada de perspectiva, produção de hipóteses, comparação, trabalhos com múltiplas temporalidades e espacialidades. Tratar da História do tempo presente nos livros didáticos também possibilitou a didatização da própria operação histórica, ao entender o presente como histórico, a população como produtora dessa História e os estudantes como agentes interpretativos dela, em concordância com os pressupostos atuais da ciência de referência.

Isto não remove ou absolve o livro didático dos jogos de poder em que está instituído, que correspondem a outras lógicas - editoriais, políticas, mercadológicas, pedagógicas - e muito menos é garantia de aprendizagem histórica, uma vez que as diferentes funções exercidas pelo livro didático estão diretamente relacionadas à sua instrumentalização e utilização. No caso da disciplina de História, é apenas uma das narrativas históricas disponíveis, da vasta cultura histórica em latência. No entanto, a existência de um compromisso do livro didático com as necessidades interpretativas do tempo presente é, em certa medida, uma possibilidade de construção de engajamento social, posicionamento crítico e consciência histórica pelos estudantes, cuja importância não se pode ignorar.

\section{Considerações Finais}

Paul Veyne discorre, a certa altura de sua clássica obra Como se escreve a história (1998), sobre os limites do trabalho do historiador ao pretender uma exposição histórica, tensionando-se infinitamente pelo peso entre uma suposta História geral como narrativa total e os acontecimentos 
que nela são considerados históricos - relevantes de análise. Para exemplificar sua tese, diz Veyne (1998, p. 48):

[...] é quase certo que um historiador morto no fim do reinado de Tibério não teria falado da paixão de Cristo: o único momento em que poderia aparecer seria na narração da agitação política e religiosa do povo judeu, onde o Cristo teria representado, e representa ainda para nós, o papel de simples figurante: é na história do cristianismo que Jesus Cristo tem o grande papel.

Em nossa compreensão, o que Veyne tinha a dizer sobre a característica irremediavelmente estrita das operações históricas feitas em um tempo ainda sendo vivido, um tempo "que ainda não terminou" (FICO, 2012) também encontra semelhanças ao tratarmos sobre a História do tempo presente produzida pelo livro didático de História. Ambas carregam, em si, possibilidades históricas, e são produzidas de acordo com o que é possível de ser operado. Constam narrativas, neste sentido, majoritariamente descritivas e baseadas nas fontes disponíveis jornalísticas -, que apresentam diferentes versões sobre as motivações para as Jornadas de Junho nos livros didáticos de História, ora analisados. Algumas versões de cunho estritamente político, outras focalizando os eventos de forma problematizadora, expondo a conjuntura a partir de diferentes ângulos: entendem sua deflagração como um ato democrático, expressivo para a visualização de problemas brasileiros, cuja motivação não é apenas política, mas também relacionada a outras esferas, e põem em destaque questões sobre a violência e a repressão dos órgãos de segurança. Outras narrativas buscam demonstrar como, em nome da governabilidade, várias reivindicações sociais foram deixadas de lado pelo governo do Partido dos Trabalhadores, o que desencadeou, conforme essa linha de abordagem, o fenômeno das Jornadas de Junho de 2013. Em algumas obras didáticas, de outra parte, o contexto inicial das Jornadas é explorado de forma a expor a historicidade do Movimento Passe Livre, ampliando o pano de fundo histórico que culminou em 2013. Em geral, identifica-se que o objetivo das autorias dos livros didáticos é entender o Brasil contemporâneo, sendo recorrente o destaque para a importância da 
participação e da manifestação popular pois, conforme explicitado em uma das obras (Coleção 18), existia a crença de que estávamos vivendo uma época em que a democracia estaria garantida no Brasil, ressaltando que os brasileiros reconhecem a cidadania e a defendem. As orientações para o professor vão no sentido de posicionar o tema numa temporalidade mais ampliada, aportando ao debate os antagonismos e as vozes dissonantes como, por exemplo, o Movimento Brasil Livre (MBL).

Para finalizar, sabemos que o livro didático de História é objeto constante de discussões públicas acerca de seu caráter ideológico e de sua suposta tendenciosidade para determinados posicionamentos políticos, práticas culturais e valores contemporâneos. Isso porque nele comparecem temas fortemente vinculados ao que teóricos contemporâneos denominam "questões socialmente vivas", assuntos que ainda estão em movimento, que não foram solidamente interpretados no âmbito da ciência nem possuem consensos acadêmicos ou sociais, razão pela qual são alvos de disputas e das diversas compreensões presentes na esfera social e nas mídias.

Uma das críticas que comumente se faz ao livro didático, sobretudo ao livro de História, é a da veiculação ideológica. Sendo entendido como um dos principais meios de organização e exposição dos conhecimentos oriundos da pesquisa acadêmica, é comum pensar-se que os conteúdos devam ser transmitidos de forma supostamente neutra e sem posicionamentos de qualquer tipo. Contudo, o livro didático não pode ser entendido fora de seu contexto social, pois ele é, conforme já afirmamos, um objeto cultural produzido segundo as normas, a lógica e a ideologia da sociedade em que está inserido. Também, é escrito de acordo com os registros epistemológicos da sua ciência de referência, a qual, por sua vez, também não é uma ciência neutra. O livro didático, como produto discursivo, é uma forma de materialização de uma determinada ideologia, portanto, não há neutralidade no discurso nem há ausência de visão de mundo nos enunciados dos agentes discursivos. Admitir a ideologia como visão de mundo significa reconhecer que a História trata, sim, da esfera política, e também da esfera econômica, social, cultural, religiosa. 
As conquistas do conhecimento humano, efetivadas ao longo das últimas décadas, apontam para a impossibilidade de haver ciência neutra e a História não configura exceção. A razão epistemológica que rege a operação histórica, notadamente no que diz respeito ao tratamento do tempo presente, no Brasil e no mundo, reconhece e valoriza a as contradições e o pluralismo em termos de posições enunciativas e pontos de vista. Tendo superado a historiografia vigente entre o século XIX e meados do século $X X$, pautada em verdades absolutas e em uma suposta neutralidade científica, os pressupostos que regem a operação histórica, atualmente, reconhecem a provisoriedade explicativa e interpretativa como elemento inerente à própria dinâmica desse conhecimento, sobre o qual se institui a cultura histórica e se constrói consciência histórica. Isso autoriza trazer para a cena do debate histórico o tempo presente, com suas aberturas e variedades de pontos de vista e posicionamentos, entendendo-o como um relevante elemento formativo que impõe consequências epistemológicas para o conhecimento que se deseja construir, indicando, claramente, a importância de vincular o ensino da História à ciência de referência, no caso, a História. Portanto, mesmo salientando o óbvio, comprova-se a diversidade de proposições didáticas, metodológicas e de concepções teóricas no conjunto das coleções aqui analisadas.

\section{Referências}

BRASIL. Guia de livros didáticos. PNLD 2017: História - Ensino fundamental/anos finais. Brasília, DF Ministério da Educação, Secretaria de Educação Básica, Fundo Nacional de Desenvolvimento da Educação, 2016. $140 \mathrm{p}$.

CERTEAU, M. de. A escrita da história. 2. ed. Rio de Janeiro: Forense Universitária, 2007.

CHAUVEAU, Agnès; TÉTART, Philippe. (org.). Questões para a história do presente. Bauru: EDUSC, 1999.

CHOPPIN, Alain. História dos livros e das edições didáticas: sobre o estado da arte. Educação e Pesquisa, São Paulo, v. 30, n. 3, p. 549-566, set./dez. 2004. 
DELGADO, Lucília de Almeida Neves; FERREIRA, Marieta de Moraes. História do tempo presente e ensino de História. Revista História Hoje, v. 2, n. 4, p. 19-34, 2013.

FICO, Carlos. História do Tempo Presente, eventos traumáticos e documentos sensíveis: o caso brasileiro. Varia História. Belo Horizonte, v. 28, n. 47, p.43-59, jan./jun. 2012.

FIGUEIRA, Divalte Garcia; VARGAS, João Tristan. História: tempo e cultura. Curitiba: Base Editorial, IBEP, 2015.

HARTOG, François. Regimes de historicidade: presentismo e experiências do tempo. Belo Horizonte: Autêntica, 2013.

HOBSBAWM, Eric. O presente como história. In: HOBSBAWM, Eric. Sobre história. São Paulo: Companhia das Letras, 2011. p. 243-255.

HOBSBAWM, Eric. O presente como história: escrever a história de seu próprio tempo. Novos Estudos CEBRAP, n. 43, p. 103-112, nov. 1995.

MEDEIROS, Josué. Breve história das Jornadas de Junho: uma análise sobre os novos movimentos sociais e a nova classe trabalhadora no Brasil. História e Perspectivas, Uberlândia, v. 51, p. 87-117, jul./dez. 2014.

MENDONÇA, Ricardo Fabrino. Dimensões democráticas nas jornadas de junho: reflexões sobre a compreensão de democracia entre manifestantes de 2013. Revista Brasileira de Ciências Sociais, v. 33, n. 98, p. 1-24, 2018.

MIRANDA, Sônia Regina; LUCA, Tânia Regina. O livro de História hoje: um panorama a partir do PNLD. Revista Brasileira de História. São Paulo, v. 24, n 48, 2004, p. 123- 144.

RIOUX, Jean-Pierre. Pode-se fazer um a história do presente? In: CHAUVEAU, Agnès; TÉTART, Philippe. (org.). Questões para a história do presente. Bauru: EDUSC, 1999. p. 39-50.

SCHERER-WARREN, Ilse. Manifestações de rua no Brasil 2013: encontros e desencontros na política. Caderno CRH, Salvador, v. 27, n. 71, p. 417-429, maio/ago. 2014.

VEYNE, Paul. Como se escreve a história. 4. ed. Brasília: Editora UnB, 1998.

As coleções são codificadas em números de 1 a 19, de modo a preservar sua vinculação aos dados apresentados. A lista das coleções inscritas no PNLD 2017 encontra-se discriminada em ordem alfabética ao final do artigo.

\section{Coleções integrantes do corpus - PNLD 2017}

ANASTASIA, Carla Maria Junho; RIBEIRO, Vanise Maria. Piatã - História. Curitiba: Editora Positivo, 2015. 
APOLINÁRIO, Maria Raquel (Editora Responsável). Projeto Araribá História. 4. ed. São Paulo: Editora Moderna, 2015.

AZEVEDO, Gislane; SERIACOPI, Reinaldo. Projeto Teláris - História. 2. ed. São Paulo: Ática, 2015.

BERUTTI, Flávio. História para nosso tempo. Curitiba: Editora Positivo, 2015.

BOULOS JÚNIOR. Alfredo. História, Sociedade \& Cidadania. 3. ed. São Paulo: Editora FTD, 2015.

BRAICK, Patrícia Ramos. Estudar História: das origens do homem à era digital. 2. ed. São Paulo: Editora Moderna, 2015.

CALAINHO, Daniela Buono; FERREIRA, Jorge. VAINFAS, Ronaldo; FARIA, Sheila de Castro. História.doc. São Paulo: Editora Saraiva, 2015.

CAMPOS, Flávio de; DOLHINIKOFF, Miriam; CLARO, Regina. História nos dias de hoje. 2. ed. São Paulo: Editora LeYa, 2015.

CARDOSO, Oldimar. História Cidadã. São Paulo: Editora AJS, 2015.

CERENCIO, Priscila (Editora Responsável). Tempo de História. 2. ed. São Paulo: Editora do Brasil, 2015.

CERQUEIRA, Célia; PONTES, Maria Aparecida; SANTIAGO, Pedro. Integralis - História. São Paulo: Editora IBEP, 2015.

COTRIM, Gilberto; RODRIGUES, Jaime. Historiar. 2. ed. São Paulo: Editora Saraiva, 2015.

FIGUEIRA, Divalte Garcia; VARGAS, João Tristan. História: tempo e cultura. Curitiba: Base Editorial, IBEP, 2015.

MOCELlin, Renato; CAMARgo, Rosiane de. Projeto Apoema - História. 2. ed. São Paulo: Editora do Brasil, 2015.

NOGUEIRA, Fausto Henrique Gomes; CAPELLARI, Marcos Alexandre; VAZ, Valéria (Editora Responsável). Universos - História. 3. ed. São Paulo: Edições SM, 2015.

PELLEGRINI, Marco César; DIAS, Adriana Machado; GRINBERG, Keila. Vontade de saber. 3. ed. São Paulo: Editora FTD, 2015.

VAZ, Maria Luísa; PANAZZO, Silvia. Jornadas.Hist - História. 4. ed. São Paulo: Editora Saraiva, 2015. 
VAZ, Valéria (Editora Responsável); MOTOOKA, Débora Yumi; BARBOSA, Muryatan Santana. Para Viver Juntos - História. 4. ed. São Paulo: Edições SM, 2015.

VICENTINO, Cláudio; VICENTINO, José Bruno. Projeto Mosaico - História. São Paulo: Editora Scipione, 2015.

Recebido em 30 de outubro de 2018

Aprovado em 19 de dezembro de 2018

História \& Ensino, Londrina, v. 24, n.2, p.163-195, jul./dez. 2018 